\title{
Giant juvenile fibroadenoma
}

Muhammet Ferhat Çelik', Ahmet Cem Dural', Mustafa Gökhan Ünsal'1, Cevher Akarsu', Elmas Reyhan Alim², Selin Kapan', Mustafa Uygar Kalaycı ${ }^{1}$, Halil Alıș ${ }^{1}$

\section{ABSTRACT}

'Clinic of General Surgery, Bakırköy Dr. Sadi Konuk Training and Research Hospital, İstanbul, Turkey

${ }^{2} C$ linic of Pediatric Surgery, Bakırköy Dr. Sadi Konuk Training and Research Hospital, İstanbul, Turkey

Address for Correspondence Muhammet Ferhat Çelik

Bakırköy Dr. Sadi Konuk Eğitim ve Araştırma Hastanesi, Genel Cerrahi Kliniği, İstanbul, Türkiye

Phone: +902124147171

e-mail:

mferhatcmd@yahoo.com

Geliş Tarihi/Received :09.12.2013

Accepted: 21.04.2014

Online Available Date: 25.12.2014

OCopyright 2015

by Turkish Surgical Association

Juvenile fibroadenoma is a common cause of breast masses seen in adolescents and young women. Giant juvenile fibroadenomas are usually single and unilateral. The etiology is thought to be due to increased levels of estrogen during adolescence, although it is not yet fully understood. Treatment options range from simple excision to subcutaneous mastectomy according to the size of the lesion. This article aimed to present a case that was diagnosed with "giant juvenile fibroadenoma".

Keywords: Giant juvenile fibroadenoma, fibroadenoma, breast

\section{INTRODUCTION}

Breast fibroadenoma defines a benign focal tumor containing both glandular and mesenchymal elements. It is usually seen in young women, at 15-25 years of age. Their growth often stops once they reach $1-2 \mathrm{~cm}$ in diameter. They are referred to as "giant fibroadenoma" when larger than $5 \mathrm{~cm}$ (1). Large size and rapid growth pattern are typical. We aimed to report a "juvenile giant fibroadenoma" case admitted to our clinic with a complaint of rapidly-growing mass in the right breast.

\section{CASE PRESENTATION}

A 10 year-old girl was evaluated at the pediatric surgery department due to a painless mass in the right breast with rapid-growth during the past month, in January 2013. Physical examination revealed a $10 \mathrm{~cm}$, hard mass with regular borders, which completely filled the right breast (Figure 1). The left breast and both axillae were normal. Her past medical and family histories were uneventful, along with normal laboratory test results. Ultrasonography (USG) of the right breast showed solid lesions of $40 \times 39 \mathrm{~mm}, 67 \times 50 \mathrm{~mm}$ and $17 \times 8 \mathrm{~mm}$ in size, which nearly completely occupied the breast, and were separated from each other by a thin echogenic septum. Doppler examination revealed arterial flow with low resistance and the lesion was classified as Breast Imaging Reporting and Data System (BI-RADS) category 3.

Breast magnetic resonance (MR) imaging showed an $87 \times 55 \mathrm{~mm}$ in size, significantly expansive, $\mathrm{T}_{1}$ hypo- and hyper-intense, $\mathrm{T}_{2}$ hyper-intense cystic-solid lesion in the right breast with dense septa and debris, with homogeneous contrast enhancement in the solid components after contrast injection, which indicated multi-compartmental benign enhancement pattern (Type A) (Figure 2).

Her tru-cut biopsy was reported as juvenile fibroadenoma. She developed minor bleeding and skin infection after biopsy, and a written informed consent was obtained for surgery after pathologic evaluation. Three lesions of about $9.5 \times 8 \times 6 \mathrm{~cm}, 4.5 \times 3.5 \times 3 \mathrm{~cm}$ and $2.5 \times 1.7 \times 1 \mathrm{~cm}$ in size were excised under general anesthesia (Figure 3). Histopathological examination of the patient was reported as giant fibroadenoma and she recovered without any problems in the postoperative period. Her routine outpatient follow-up USG evaluation at 6 months after surgery was normal (Figure 4).

\section{DISCUSSION}

Juvenile fibroadenoma is a common cause of breast masses in adolescents and young women. Although usually solitary, $10-20 \%$ may be multiple (2). Breast fibroadenoma is often diagnosed the $2^{\text {nd }}$ and $3^{\text {rd }}$ decades, and its growth typically ceases once it reaches up to $2-3 \mathrm{~cm}(1)$. Juvenile giant fibroadenoma is usually single and unilateral, but may also be bilateral (2). It is well contoured and encapsulated, therefore, is usually benign. It is frequently characterized by reaching to large sizes with rapid growth (3). Although the etiology is considered to be due to increased estrogen levels during adolescence, the exact cause is not yet fully known $(4,5)$. Such lesions may lead to compression 


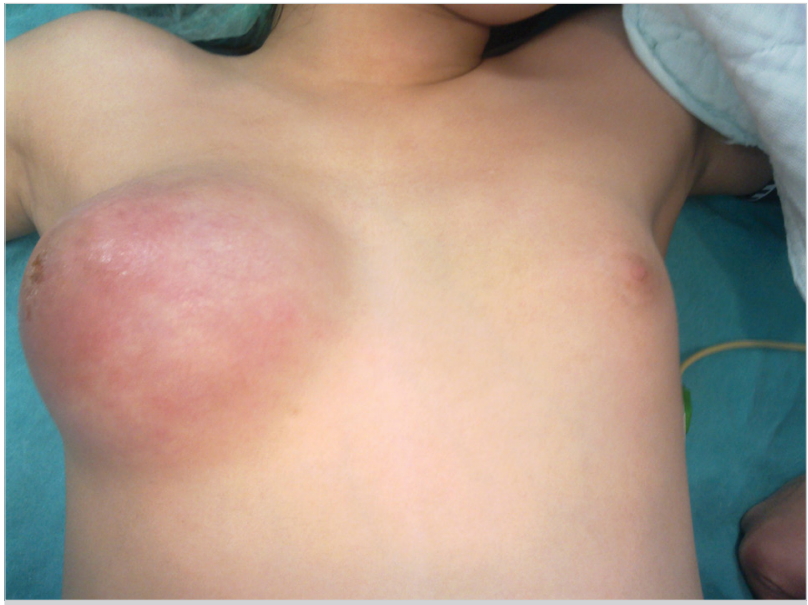

Figure 1. Preoperative view of the patient

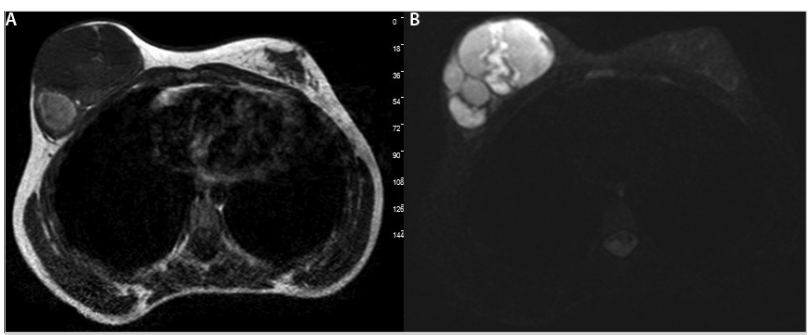

Figure 2. $T_{1}$ hypo- and hyper-intense (2A), $T_{2}$ hyperintense cystic-solid lesion with dense septa and debris, with homogeneous contrast enhancement in the solid components after contrast injection (2B)

in the surrounding tissue, deterioration in breast structure, nipple retraction and expansion of superficial veins due to size increase (6).

Breast phyllodes tumors usually occur in women between 35-55 years of age (7). Although similar to fibroadenomas, they are differentiated with increased cellularity and increased tendency to recur and metastasize. USG is generally sufficient for diagnosis; nevertheless, MR is performed in few cases. The reason for obtaining an MR in our patient was the emergence of the mass in one month.

Prior to surgical excision, knowing the pathology of breast lesions is especially important to differentiate phyllodes or malignant tumors. The treatment options of juvenile fibroadenomas vary from simple excision to subcutaneous mastectomy depending on the size of the mass. Unique to our patient, following excision of three fibroadenomas that were quite large, breast symmetry was acceptable without requiring additional reduction or skin excision. In our patient, the surgical incision had to be extended over the areola at the medial side, due to the infection that occurred after biopsy, however, there was no tissue loss at the areola. We believe this problem may be avoided by placing the incision $1-2 \mathrm{~cm}$ away from the areola.

\section{CONCLUSION}

Juvenile giant fibroadenomas can influence mammary gland development by the pressure effect due to their enormous

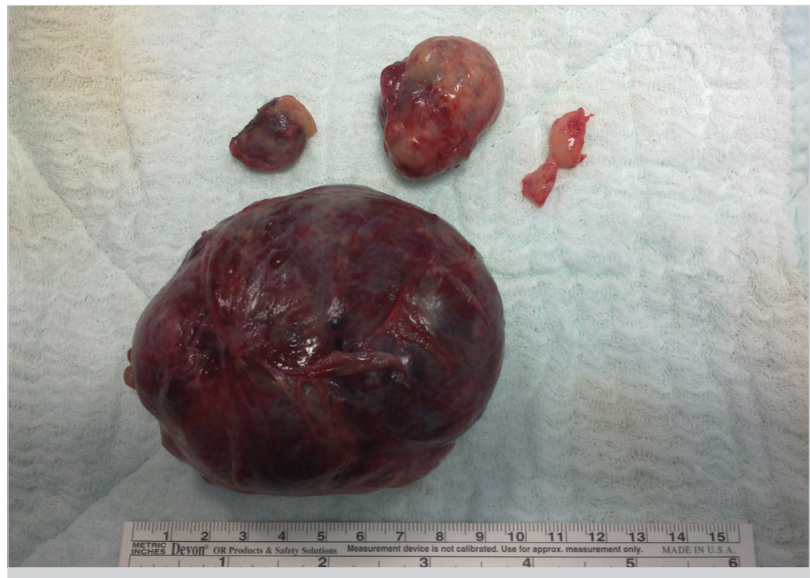

Figure 3. Macroscopic view of the excised giant fibroadenoma specimen

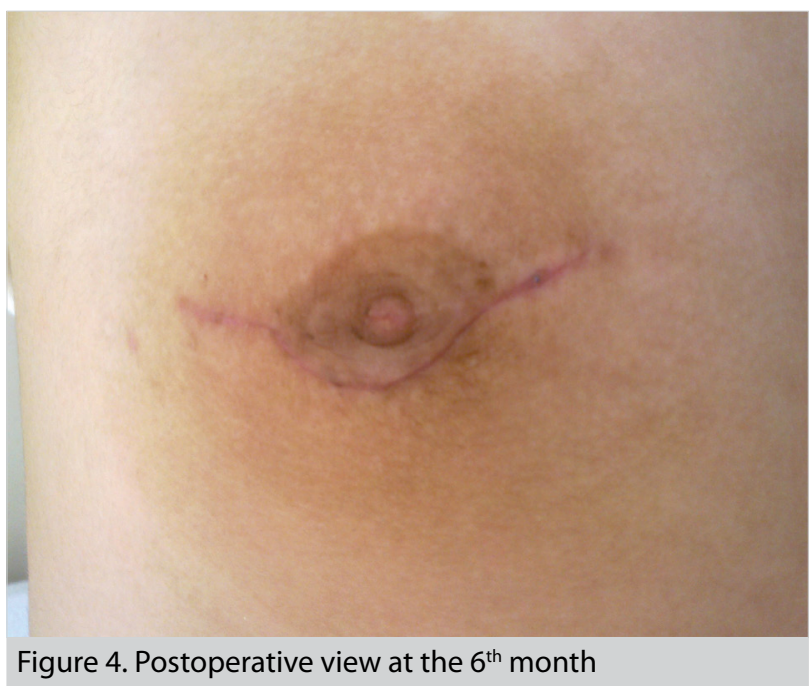

size. Surgical treatment offers complete cure and acceptable cosmetic results.

Informed Consent: Written informed consent was obtained from patient who participated in this case.

Peer-review: Externally peer-reviewed.

Author Contributions: Concept - M.F.Ç., M.G.Ü., E.R.A.; Design M.F.Ç., E.R.A., S.K.; Supervision - S.K., M.U.K., H.A.; Funding - M.F.Ç., E.R.A., S.K.; Materials - M.F.Ç., E.R.A.; Data Collection and/or Processing - M.G.Ü., C.A., E.R.A.; Analysis and/or Interpretation - A.C.D., C.A.; Literature Review - M.F.Ç., A.C.D.; Writer - M.F.Ç., M.G.Ü., E.R.A.; Critical Review - S.K., M.U.K., H.A., A.C.D.; Other - C.A.

Conflict of Interest: No conflict of interest was declared by the authors.

Financial Disclosure: The authors declared that this study has received no financial support.

\section{REFERENCES}

1. Brunicardi FC, Andersen DK, Billiar TR, Dunn DL, Hunter JG, Pollock RE. Breast. Schwartz SI. Principles of Surgery. 9th ed. New York: McGraw-Hill; 2009. p. 797-915. 
Çelik et al.

Giant juvenile fibroadenoma

2. Matz D, Kerivan L, Reintgen M, Akman K, Lozicki A, Causey $T$, et al. Breast preservation in women with giant juvenile fibroadenoma. Clin Breast Cancer 2013; 13: 219-222. [CrossRef]

3. Thuruthiyath N, Das PC, Avabratha KS, Mascarenhas V, Marla N. Giant fibroadenoma of breast in an adolescent girl. Oman Med J 2012; 27: 314-315. [CrossRef]

4. Çalışkan M, Acar A, Erdem H, Kurt MD, Subaşı IE, Alimoğlu O. Juvenile giant fibroadenoma: Case report. Ümraniye Tıp Dergisi 2010-2011; 3-4: 17-19.
5. Park CA, David LR, Argenta LC. Breast asymmetry: presentation of a giant fibroadenoma. Breast J 2006; 12: 451-461. [CrossRef]

6. Hawary MB, Cardoso E, Mahmud S, Hassanain J. Giant breast tumors. Ann Saudi Med 1999; 19: 174-176.

7. Reinfuss M, Mitus J, Duda K, Stelmach A, Rys J, Smolak K. The treatment and prognosis of patients with phyllodes tumor of the breast: an analysis of 170 cases. Cancer 1996; 77: 910-916. [CrossRef] 